\title{
PERSPECTIVAS NO ÂMBITO CIENTÍFICO, TECNOLÓGICO E SOCIAL ABORDADOS NO CONTEXTO EDUCACIONAL
}

Perspectives on scientific scope, technological and social addressed in educational context

\author{
Angélica Ramos da Luz; \\ Daniela Brusamarelo; \\ Dilene Gomes de Miranda; \\ Luciene Lima de Assis Pires. ${ }^{1}$
}

\begin{abstract}
RESUMO: No presente artigo, enfoca-se a ciência, tecnologia e a sociedade na perspectiva do contexto educacional. Sem a pretensão de esgotar o tema, são abordados quatro momentos da CTS, interligados por questões sociais, econômicas, ambientais, científicas. Inicialmente é exposto o contexto capitalista na visão de Marx e a ciência dos séculos XVII, XVIII, à contemporaneidade. Em seguida, destacou-se a influência do termo CTS apresentado em diferentes contextos, tendo como perspectiva compreender como ganhou força, de que maneira foi inserido no ambiente educacional. Na sequência, a alfabetização científica foi abordada como um caminho para o desenvolvimento da criticidade no indivíduo, denotando sua necessidade premente. Em sua parte final, foi exposta breve revisão de autores sobre caminhos e possibilidades do enfoque CTS no ensino de Ciências.
\end{abstract}

PALAVRAS-CHAVE: Enfoque CTS, Ensino de Ciências, Alfabetização Científica.

\begin{abstract}
In this article, science, technology and society are analyzed in a broad view that is within the educational context. It is presented here four CTS focus of moments that are interconnected by social, economic, environmental and scientific issues. At first analyzed the capitalist society in the view of Marx and the rise of science as the protagonist of the seventeenth and eighteenth centuries. Then analyzed the influence of the term CTS presented in different contexts, and an attempt to understand how gained strength, how was inserted in the educational context. Thirdly, it was established how the technology was effective in the twentieth century, addressing its real importance to society because of sudden technological advances, resulting in the need for scientifically literate. Finally he sought to understand the relationship between the CTS focus on science education, from its inception to its practice nowadays.
\end{abstract}

KEYWORDS: CTS Focus, science education, Scientific Literacy.

\footnotetext{
${ }^{1}$ Instituto Federal de Goiás - Campus Jataí.
} 


\section{INTRODUÇÃO}

O objetivo desse artigo é expor uma breve revisão do Enfoque CTS no âmbito do desenvolvimento da ciência, da tecnologia, da sociedade, os caminhos possíveis para a educação na perspectiva de uma alfabetização científica.

Nesse sentido, apresentam-se aspectos da Ciência e Tecnologia (C\&T) na visão de Marx, que debateu sobre a sociedade capitalista e a forma com que o processo evolutivo da ciência contribui para alavancar a desigualdade. Propõe-se a interação entre ciência, tecnologia e sociedade, tendo em vista que ambas estão interligadas e por isso devem ser trabalhadas de maneira que contemple a visão do todo. Também se buscou relacionar a alfabetização científica com a necessidade de construção do cidadão crítico, e para isso, utiliza-se da proposta do enfoque CTS no ensino de ciências, visando justamente essa contemplação e dinâmica, permitindo que o indivíduo se perceba parte integrante desse processo evolutivo e, como tal, é importante que compreenda e analise suas ações.

\section{Ciência e Sociedade: os clássicos e o terceiro milênio}

Para compreendermos a ciência é necessário interpretar a sociedade em que vivemos e, nesse sentido a teoria marxista de sociedade é, fundamentalmente, uma teoria crítica radical da sociedade capitalista. Dessa forma, o processo de vida social, política e intelectual é condicionado pelo modo de produção, ou seja, não é a consciência dos homens que determina a realidade; ao contrário, é a realidade social que determina sua consciência (IANNI, 1988)².

Ao propor uma mudança no âmbito social é fundamental conhecer a realidade de todos os indivíduos, sendo necessário estar inserido nessa sociedade para analisar as possibilidades de atuação, compreender os níveis hierárquicos e de subordinação presente no ambiente.

Os estudos de Marx sugerem que, sem a dialética, não seria possível pensar e transformar o capitalismo. Isto é, enquanto que a dialética idealista hegeliana é um método de pensar o real, a dialética marxista é um método de pensar e transformar o real. A interpretação dialética opera na constituição e transformação da realidade, ao mesmo tempo em que a interpreta (IANNI, 1988).

Em contrapartida, com uma sociedade transformada está a ciência, que passa a ser a base para entendermos os fenômenos naturais e boa parte do que acontece em nosso meio. Os autores Jarrosson $(1996)^{3}$ e Fourez $(1995)^{4}$ também evidenciam a relação da ciência com a

\footnotetext{
2 IANNI, O. Dialética e capitalismo. 3. ed. Petrópolis: Vozes, 1988, p. 11-40.

${ }^{3}$ JARROSSON, B. Humanismo e técnica: o bumanismo entre economia, filosofia e ciência. Lisboa: Instituto Piaget, 1996, p. 1661.
} 
sociedade, em uma visão que nos conduz a refletir sobre a relação do homem com a natureza e os motivos que buscam desvendar seus fenômenos.

Para Jarrosson (1996), a ciência moderna possibilita o desenvolvimento tecnológico que é utilizado para a dominação da natureza. Ao romper com a filosofia grega o qualitativo é eliminado e a quantidade tem poder para representar a qualidade. O conhecimento científico do mundo torna-se um conhecimento por procuração.

Fourez (1995), por sua vez, destaca que a ciência em evolução constante possibilita o desenvolvimento do progresso e as mudanças que ocorrem com as tecnologias apresentam novas visões da sociedade. Acrescenta, ainda, que a ciência e a tecnologia têm participação na organização da sociedade contemporânea e provoca mudanças. Não se imagina hoje uma sociedade sem energia, meios de comunicação, eletrodomésticos dentre outros, na medida em que a ciência é sempre uma possibilidade de certo domínio da natureza.

Ao retomar os séculos XVII e XVIII, evidencia-se uma ciência que se restringia à apenas alguns grupos sociais, eram poucos os que tinham acesso ao conhecimento. A ciência estava vinculada a burguesia e, por esse motivo, um dos interesses da comunidade científica era ter controle sobre a ciência, o que resulta em uma relação de poder entre os que detinham o conhecimento e certamente a outra parcela da população que não fazia parte deste meio científico.

No limiar do século XX, a ciência promove a continuidade de uma visão mecanicista do mundo. No entanto, esta concepção se encontra em transição, pois, a quantificação da natureza já não se assenta em um conhecimento objetivo. O processo de mediação entre ciência e sociedade não é neutro. O número já não representa o real por procuração e, aos poucos, fomos percebendo que a ciência está inserida no contexto social (JARROSSON, 1996).

Nesse sentido, os meios de comunicação contribuem para esta percepção da realidade ao divulgarem descobertas e curiosidades sobre a Ciência Contemporânea e a Física Moderna. As disciplinas ofertadas pelas instituições de ensino, por sua vez, trazem uma visão colaborativa da ciência com a sociedade sendo propostas ações voltadas para o envolvimento do aluno com pesquisas relacionadas ao aspecto ambiental, social, tecnológico e científico.

Embora a Ciência Contemporânea amplie o nosso conhecimento de mundo, a prática científica que proporciona essa compreensão não é acessível de forma igualitária às sociedades mundiais. Os avanços decorrentes da evolução científica são privilégios de poucos países. Nesse sentido, os avanços em termos de disseminação da ciência e os caminhos a que conduzem a sociedade necessita progredir. Os debates sobre a importância da formação científica nas escolas,

${ }^{4}$ FOUREZ, G. A construção das ciências: introdução à filosofia e a ética das ciências. São Paulo: Editora Unesp, 1995. 
universidades e demais instituições, para a promoção da compreensão da CTS, se constituem em oportunidade para essa efetivação.

A ciência influencia a sociedade, a filosofia, as visões do mundo, os modos de organização social, a economia. Ao possibilitar novos meios de conhecimento influencia diretamente o comportamento do indivíduo.

\section{A educação no contexto da Ciência, Tecnologia e Sociedade}

O conceito de Ciência, Tecnologia e Sociedade (CTS) apresenta-se em diferentes contextos, dentre eles estão o político, o econômico, o cultural, o ético. Nessa perspectiva, é fundamental compreender como o termo CTS ganhou força, de que maneira vem sendo inserido nas escolas e qual sua relevância. A formação científica contribui ao proporcionar a alfabetização do indivíduo com conhecimentos científicos e tecnológicos partindo do contexto social.

Para relativizar a compreensão sobre ciência, Fonseca $(2007)^{5}$, utiliza a Sociologia do Conhecimento Científico para explicar que a ciência é feita a três, pois existe uma relação entre o sujeito/cientista, seu objeto de estudo e também as interações e relações que se estabelecem no processo de produção de verdade científica. Com essa afirmação, entende-se que a construção do termo CTS já era estudada para equilibrar a relação entre o homem e a natureza.

A ciência não está mais sendo entendida como a busca de domínio do mundo, como aponta Fonseca (2007). Ela está em nosso cotidiano, fazendo-se presente, criando circunstâncias para tornar-se ainda mais indispensável à sociedade, porém, há que se considerar o preço de tamanha eficiência. As modificações planetárias, a escassez de recursos naturais, a mudanças de hábitos de consumo da sociedade também são reflexos desta evolução científica e tecnológica.

Em seu artigo Enfoque Ciência-Tecnologia-Sociedade: pressupostos para o contexto brasileiro, Auler (2007. p. 01) $)^{6}$ destaca alguns objetivos da educação CTS que visam:

[...] promover o interesse dos estudantes em relacionar a ciência com aspectos tecnológicos e sociais, discutir as implicações sociais e éticas relacionadas ao uso da ciência-tecnologia (CT), adquirir uma compreensão da natureza da ciência e do trabalho científico, formar cidadãos científica e tecnologicamente alfabetizados capazes de tomar decisões informadas e desenvolver o pensamento crítico e a independência intelectual.

\footnotetext{
${ }^{5}$ FONSECA, A. B. Ciência, tecnologia e desigualdade social no Brasil: contribuições da sociologia do conhecimento para a educação em ciências. Revista Electrónica de Enseñanza de las Ciencias, vol. 6, n. 2, 2007, p. 364-377.

${ }^{6}$ AULER, D. Enfoque ciência-tecnologia-sociedade: pressupostos para o contexto brasileiro. Ciência e Ensino, vol. 1, número especial, novembro, 2007.
} 
Os objetivos propostos são bem fundamentados, mas ainda é algo que está posto somente no papel. Além de criar objetivos é primordial efetivar metas para que de fato ocorram mudanças nas metodologias de ensino.

Auler (2007) debate o uso de temas geradores, que são estratégias de ensino por meio de investigação temática, como forma de trabalhar nas escolas a educação CTS, evidenciando uma possibilidade de sucesso. Esses temas são um caminho possível para despertar o interesse do aluno e contextualizá-lo em uma realidade que é local, regional, global. Como exemplos de ações para a educação CTS efetivadas nas escolas são destacados a feira de ciências, a mostra cultural e científica.

Um fator determinante para a promoção da educação CTS é justamente o resgate do interesse e a participação do aluno ao realizar ações além do contexto da sala de aula. A educação em uma perspectiva CTS transforma o ambiente em um universo mágico repleto de possibilidades, desafios. A sua efetivação, porém, depende de vários fatores, dentre eles, a formação continuada do professor, a flexibilização do currículo, ou seja, a implementação de políticas educacionais e governamentais que possibilitem este ensino.

A persistente e histórica separação entre as denominadas ciências naturais e ciências humanas influenciam na aprendizagem, fragmentando o conhecimento, e até mesmo na relação entre a CTS e as disciplinas, o que dificulta trabalhar com as relações sociais interpostas à técnica. Nesse sentido, a interdisciplinaridade é um caminho para transpor barreiras historicamente construídas entre os professores de áreas de ensino diversas e integrar o conhecimento.

Bazzo (1998, p. 136) ${ }^{7}$ em seu texto Ciência, tecnologia e sociedade e suas implicações, reforça que:

[...] é preciso acabar com o hiato existente principalmente entre o campo do conhecimento tecnológico e o campo de conhecimento das ciências sociais. Nossa sociedade sempre deixou transparecer a existência de uma crescente separação entre duas culturas que constantemente resultou em entrave para a aproximação indispensável entre os mais diversos campos de saber.

Nesse sentido, Auler (2007) salienta que uma leitura crítica da realidade se faz necessária para a compreensão das interações entre CTS, visto que a sociedade está fortemente marcada pela Ciência e Tecnologia, não se preocupando com o todo. O que possivelmente seja fator limitante para a formação do cidadão crítico e atuante, tornando de extrema importância o estímulo, o despertar da curiosidade, da pergunta.

Para que ocorra uma mudança dessa amplitude na formação do aluno e no ensino, Bazzo (1998), categoricamente afirma que devemos retirar a ciência e a tecnologia de seus pedestais

\footnotetext{
${ }^{7}$ BAZZO, W. A. Ciência, tecnologia e sociedade e o contexto da educação tecnológica. Florianópolis: Editora da UFSC, 1998, p.
} 136-144. 
inabaláveis da investigação desinteressada da verdade e dos resultados generosos para o progresso humano.

Dessa forma, o conformismo e a falta de avaliação crítica geram as dúvidas, os questionamentos e as incertezas em relação à utilização e o desenvolvimento da ciência e tecnologia a favor da sociedade. Bazzo (1998), também reforça que as dúvidas somente serão sanadas, quando recebermos uma formação razoável nos preceitos científicos e tecnológicos e nas suas consequências e repercussões.

As diversas novidades no campo científico e tecnológico atraem inúmeros seguidores, que nem sempre entendem o porquê de um novo aparato tecnológico, por isso se faz necessária à alfabetização científica para deixarmos de ser apenas consumidores desses produtos e passarmos a entender sua real aplicabilidade para nós.

É importante ressaltar que a ciência e a tecnologia trouxeram contribuições que proporcionam conforto, por meio da aquisição de bens de consumo, facilidades de comunicação, de disseminação da informação para a sociedade. Os eletrodomésticos, a internet, o celular são exemplos que ilustram esse contexto. No entanto, Bazzo (1998, p. 143-144), faz um alerta sugestivo de que:

[...] para encarar as novas tecnologias e trabalhar os seus impactos sem medos e sem ufanismo: cautela, uma boa dose de reflexão de suas vantagens e limitações, e acima de tudo uma contextualização das suas implicações. Se a revolução industrial causa problemas até hoje sentidos - poluição, degradação ambiental, acumulação de capital, exploração de trabalho humano - ela também permite confortos de que ninguém quer abdicar - medicamento, televisão, carro, telefone, geladeira. Se a imprensa desempregou os monges copistas, ela também permite hoje que cada aluno tenha o seu livro, que todos possam ler jornais diariamente e que se montem bibliotecas em cada cidade ou em cada escola.

Em nosso contexto, a ciência e a tecnologia são importantes para a sociedade, mas é fundamental assumirmos um posicionamento crítico e reflexivo para que possamos viver cercados por técnicas e tecnologias. Devemos pensar que nem todos os problemas são de caráter científico-tecnológico e que, por esse motivo, as criações da tecnologia não servem apenas para melhorar a vida.

Portanto, a educação e a forma como ensinar devem se pautar no pensamento crítico, na valorização cultural, moral e subjetiva do indivíduo. Essa metodologia deve ser dinamizada, acessível a todos independente do conhecimento, etnia, religião.

\section{Alfabetização Científica: construção do pensamento crítico}


Para estabelecer uma relação entre o aluno e a ciência, é preciso conhecer os caminhos que se fazem presentes no meio científico, buscando promover a alfabetização científica que se faz necessária na construção do cidadão crítico e consciente.

Partindo do aspecto social, a alfabetização científica deve acontecer principalmente nas instituições de ensino, pois se constituem em principais meios que propiciam a formação científica do indivíduo.

Com o crescente desenvolvimento tecnológico, a população utiliza com maior frequência ferramentas decorrentes desta evolução, permitindo afirmar que fomos ao longo dos anos habituados ao uso destes recursos e, por esse motivo, não conseguimos nos desvincular. Os produtos tecnológicos prendem a atenção, facilitam a vida, e, no entanto proporcionam descontentamentos. Nesse sentido, Cachapuz et al. $(2011, \text { p. } 18)^{8}$ afirma:

Num mundo repleto pelos produtos da indagação científica, a alfabetização científica converteu-se numa necessidade para todos: todos necessitamos utilizar a informação científica para realizar opções que se nos deparam a cada dia; todos necessitamos ser capazes de participar em discussões públicas sobre assuntos importantes que se relacionam com a ciência e com a tecnologia; e todos merecemos compartilhar a emoção e a realização pessoal que pode produzir a compreensão do mundo natural.

A alfabetização científica deixou de ser necessária apenas para estudantes e passou a ser essencial para a sociedade. Não vivemos alheios aos acontecimentos do mundo, esses acontecimentos estão relacionados ao desenvolvimento de um novo produto tecnológico, a comercialização de um medicamento revolucionário e até mesmo questões referentes ao meio ambiente.

Para nos posicionarmos contra ou a favor de alguma lei, decreto e até mesmo em debates entre amigos e familiares, é fundamental nos apropriarmos das informações válidas transformando-as em conhecimento.

Por esse motivo Cachapuz et al. (2011), acredita ser necessário fomentar e difundir a alfabetização científica em todas as culturas e em todos os setores da sociedade, o que promoveria a participação dos cidadãos em decisões relativas à aplicação de novos conhecimentos.

Apesar de sua importância, ainda há uma enorme barreira entre ciência e sociedade, podendo ser constatado na insatisfação que estudantes apresentam pelas disciplinas de Química, Física, Biologia e Matemática. Em parte, essa insatisfação está nas metodologias adotadas para o

\footnotetext{
${ }^{8}$ CACHAPUZ, A.; GIL-PÉREZ, D.; CARVAlHO, A. M. P.; PRAIA, J.; VILCHES, A. A necessária renovação do ensino das ciências.3. ed. São Paulo: Cortez, 2011, p. 18-27.
} 
ensino de ciências, sendo apontada como um dos fatores a falta de contextualização entre o conteúdo que está sendo ensinado e o contexto no qual o aluno se insere.

Em contrapartida Gil-Pérez e Vilches (apud Cachapuz et al., 2011, p. 27) defendem que:

O prejuízo foi e continua a ser que a "maioria da população é incapaz de aceder aos acontecimentos científicos, que exigem um alto nível cognitivo", o que implica, obviamente reservá-los a uma pequena elite. A recusa da alfabetização científica recorda assim a sistemática resistência histórica dos privilegiados à extensão da cultura e à generalização da educação.

A proposta de formação científica está inteiramente associada ao despertar do espírito crítico, elucidando uma aventura ao conhecimento, interagindo com problemas presentes na sociedade e tentativas de construção de soluções. Mas para se chegar a esse nível, Cachapuz et al. (2011) acredita ser necessária a superação de visões distorcidas da ciência e tecnologia enraizadas desde o início do processo de ensino.

$\mathrm{Na}$ intenção de construir uma leitura de mundo crítica e verdadeira, Santos e Mortimer $(2002)^{9}$ apontam ser fundamental para o aluno entender a natureza da ciência e suas implicações sociais, isso remete à necessidade de contemplar nos currículos aspectos relacionados à filosofia, história e sociologia das ciências.

Logo, a alfabetização científica não está diretamente relacionada ao aprendizado de fórmulas e conceitos, ela vai além de reproduções. A proposta está voltada para uma visão ampla da ciência, que envolva não apenas o aspecto científico, mas também o tecnológico, o ambiental e principalmente o social, pois as ações refletem na sociedade de alguma forma.

\section{O Enfoque CTS no Ensino de Ciências}

O movimento CTS ganhou um impulso mais significativo quando a sociedade começou a questionar os discursos sobre o progresso e o desenvolvimento advindos da Ciência e Tecnologia (C\&T), sem uma análise crítica das relações de seus conhecimentos. O período subsequente a Segunda Guerra Mundial foi marcada por um avanço muito rápido da C\&T, que possibilitou conquistas importantes, como o desenvolvimento de remédios mais eficazes, a criação de novos produtos, o controle de doenças e pragas, o aumento da produtividade agrícola, a conquista do espaço, o desenvolvimento de sistemas de gerenciamento de informações. Tudo isso propiciou um aumento da qualidade e da expectativa de vida. Essa aceleração do avanço tecnológico

\footnotetext{
${ }^{9}$ SANTOS, W.L.P.; MORTIMER, E. F. Uma análise de pressupostos teóricos da abordagem C-T-S no contexto da educação brasileira. Revista Ensaio-Pesquisa em Educação em Ciências, vol. 2, n. 2, dezembro, 2002.
} 
provocou um sentimento geral de crença na superioridade do conhecimento científico (SANTOS et al., 2011) ${ }^{10}$.

Os estudos CTS no campo educacional surgiram associados ao ensino de Ciências, com a proposição, a partir da década de 70 , de novos currículos que buscaram incorporar conteúdos de CTS. Diversos materiais didáticos para o ensino de Ciências foram produzidos com enfoque CTS para todos os níveis educacionais, desde o Ensino Fundamental à Graduação, em diversos países (SANTOS et al.).

O enfoque CTS, segundo Santos et al. (2011), abrange desde um entendimento que considera as interações CTS como fator motivacional para Ensino de Ciências até aquele que o coloca como fator essencial à compreensão científica. Há também interpretações que responsabilizam o enfoque CTS por um esvaziamento do conhecimento científico trabalhado em sala de aula, o que remete a falta de teoria, enrolação do conteúdo.

No ensino de Ciências, exige-se uma base de conteúdos articulada com questões relativas a aspectos científicos, tecnológicos, sociais, econômicos e políticos. De acordo com Santos et al. (2011), essa articulação fará com que os aprendizes, atores sociais, apropriem-se de ferramentas culturais para atuar de forma participativa no mundo em que estão inseridos, referindo-se ao desenvolvimento da capacidade de tomada de decisão.

Para Santos et al. (2011), a tomada de decisão relaciona-se à solução de problemas da vida real em seus amplos aspectos, o que significa preparar o indivíduo para participar ativamente na sociedade. Além disso, o ensino de CTS tem como propósito compreender as potencialidades e limitações do conhecimento científico por meio dos conhecimentos básicos de ciências.

Nesse sentido, SANTOS et al., (2011, p. 140) afirma que o enfoque CTS pretende:

a) analisar e desmitificar o papel da ciência e da tecnologia como conhecimento hierarquizado e que leva ao desenvolvimento; b) a aprendizagem social da participação pública nas decisões relacionadas com os temas tecnocientíficos e c) uma renovação de estrutura curricular dos conteúdos, de forma a colocar a C\&T em concepções vinculadas ao contexto social.

Considerando que a educação não é neutra, Auler (2002) defende a necessidade de profundas mudanças no campo curricular, a fim de fazer com que o ensino de CTS não seja empregado somente como mero fator de motivação no processo de cumprir programas, de vencer conteúdos.

Nesse viés, ao buscar um ensino de Ciências inserido numa concepção transformadora e progressiva de educação, deve-se debater a formação de professores, associando ao ensino de

\footnotetext{
${ }^{10}$ SANTOS, W. L. P.; GALIAZZI, M. C.; JUNIOR, E. M. P.; SOUZA, M. L.; PORTUGAL, S. “O enfoque CTS e a educação ambiental: possibilidade de "ambientalização" da sala de aula de ciências". In: SANTOS, W.L.P.; MALDANER, O. A. (Orgs.). Ensino de química em foco. Ijuí: Unijuí, 2011, p. 133-141.
} 
conceitos científicos a problematização das construções historicamente realizadas sobre a atividade científico-tecnológica (SANTOS et al.).

Logo, a pesquisa sobre a prática pedagógica do professor é importante para que se avance na compreensão de como melhor desenvolver o enfoque CTS em sala de aula. Para isso, SANTOS et al.(2011), ressalta que esse tipo de compreensão deve ser favorecido em grupo de pesquisa/formação de professores por meio do debate sobre a proposta pedagógica do mesmo.

\section{Considerações Finais}

Observando os aspectos no qual a ciência e a tecnologia estão presentes na sociedade, percebe-se a evolução do homem, no sentido de progresso, bastando olhar para tudo o que já foi feito por meio de estudos, que deu origem a ciência e posteriormente a tecnologia, que também é resultado do conhecimento humano.

Logo, as criações humanas podem tornar novos mecanismos de estudo, como é o caso do enfoque CTS, que têm se feito presente na construção da alfabetização científica no ensino de ciências, descobrindo maneiras para vivermos harmonicamente no planeta, pois, o ser humano necessita se perceber como parte integrante do todo, e como tal, deve se formar socialmente, cientificamente e tecnologicamente a fim de contribuir e não apenas destruir.

\section{REFERÊNCIAS}

AULER, D. Enfoque ciência-tecnologia-sociedade: pressupostos para o contexto brasileiro. Ciência e Ensino, vol. 1, número especial, novembro, 2007.

BAZZO, W. A. Ciência, tecnologia e sociedade e o contexto da educação tecnológica. Florianópolis: Editora da UFSC, 1998.

CACHAPUZ, A.; GIL-PÉREZ, D.; CARVAlhO, A. M. P.; PRAIA, J.; VILCHES, A. A necessária renovação do ensino das ciências. 3. ed. São Paulo: Cortez, 2011.

CALVINO, I. Por que ler os clássicos. São Paulo: Companhia das Letras, 1993.

FONSECA, A. B. Ciência, tecnologia e desigualdade social no Brasil: contribuições da sociologia do conhecimento para a educação em ciências. Revista Electrónica de Enseñanza de las Ciencias, vol. 6, n. 2, 2007, p. 364-377.

FOUREZ, G. A construção das ciências: introdução à filosofia e a ética das ciências. São Paulo: Editora Unesp, 1995.

IANNI, O. Dialética e capitalismo. 3. ed. Petrópolis: Vozes, 1988, p. 40. 
JARROSSON, B. Humanismo e técnica: o humanismo entre economia, filosofia e ciência. Lisboa: Instituto Piaget, 1996, p. 16-61.

LATOUR, B. A ciência em ação: como seguir cientistas e engenheiros sociedade afora. São Paulo: Editora Unesp, 2000.

SANTOS, W. L. P.; GALIAZZI, M. C.; JUNIOR, E. M. P.; SOUZA, M. L.; PORTUGAL, S. “O enfoque CTS e a educação ambiental: possibilidade de "ambientalização" da sala de aula de ciências". In: SANTOS, W.L.P.; MALDANER, O. A. (Orgs.). Ensino de química em foco. Ijuí: Unijuí, 2011, p. 131-141

SANTOS, W.L.P.; MORTIMER, E. F. Uma análise de pressupostos teóricos da abordagem C-TS no contexto da educação brasileira. Revista Ensaio-Pesquisa em Educação em Ciências, vol. 2, n. 2, dezembro, 2002.

VAZ, C. R.; FAGUNDES, A. B.; PINHEIRO, N. A. M. O surgimento da ciência, tecnologia e sociedade (CTS) na educação: uma revisão. Anais do I Simpósio Nacional de Ensino de Ciência e Tecnologia, Curitiba, 2009. ISBN: 978-85-7014-048-7. 